\title{
The effect of training on aerobic and anaerobic critical velocities in young swimmers
}

\begin{abstract}
The purpose of the current study was to analyze the aerobic and anaerobic critical velocities in young swimmers throughout a period of 42 weeks of training. The sample comprised twelve swimmers, 8 males and 4 females (mean \pm SD: $15.6 \pm 1.78$ years of age, $61.33 \pm 7.9$ $\mathrm{kg}$ of body mass, $1.68 \pm 0.09 \mathrm{~m}$ of height and $168.25 \pm 8.9 \mathrm{~kg} / \mathrm{m}^{2}$ of body mass index). The performances were assessed in $15 \mathrm{~m}, 25 \mathrm{~m}, 50 \mathrm{~m}$ and $400 \mathrm{~m}$ freestyle once a month during all season. To verify the normal distribution was performed Shapiro-Wilk test and a pairedsample t-test was used to analyze the aerobic and anaerobic critical velocities throughout the training period. The results demonstrated significant improvements of aerobic critical velocity at week 35 , and at the weeks 21,35 and 40 for the anaerobic critical velocity. In addition, there seemed to be some negative relationship between aerobic and anaerobic training, since the maximization of one seems to coincide with the low performance level of the other.
\end{abstract}

Keywords: critical velocity, aerobic, anaerobic, training control
Volume 4 Issue 3 - 2019

\author{
Henrique P Neiva, Pedro Dias, Daniel A \\ Marinho \\ Research Center in Sports Sciences, Health Sciences and \\ Human Development, University of Beira Interior, Portugal
}

Correspondence: Daniel A. Marinho, UBI- Sports Sciences Departament, Convento de Santo António. 620I-00I Covilhã, Portugal,Email dmarinho@ubi.pt

Received: May 09, 2019 | Published: June 05, 2019

\section{Introduction}

The improvement on swimmers 'performance during a season can be mainly due to the optimization of training process, caused by an efficient monitoring and training control. ${ }^{1}$ Coaches should have a deep knowledge of all the parameters and variables that will influence sports performance so that they can better design a training program, aiming for improvement of performances throughout the season. ${ }^{2}$ Reis and Alves ${ }^{3}$ and Leite et al. ${ }^{4}$ emphasized that the structure of the training plan needs to be continuously followed up and adjustments should be made according to the improvement or not of performance and according to the swimmers' responses to training loads. For example, according to Marinho et al. ${ }^{5}$ the training process efficiency appears deeply determined by the possibility of collecting data about the evolution and needs of each swimmer.

The physiological variables are those usually those that are evaluated throughout a season to understand the swimmer response. However, most of physiological and performance assessments require for expensive tools and time. In alternative, there has been a development of other assessments, reliable, easy to apply and without extra costs for the swimming clubs, as the example of critical velocity determination. The concept of critical velocity was introduced and adapted for swimming by Wakayoshi et al. ${ }^{6}$ by the original concept of critical power proposed by Monod and Scherrer. ${ }^{7}$ These authors also stated that the critical power value is obtained from the slope of the regression line between the total work performed (application of a force along a displacement) and the total time spent until exhaustion. The critical velocity was defined as the maximum velocity that can be maintained for a long period of time in the absence of exhaustion. ${ }^{6}$

Increasingly, the critical velocity has been used for swimming coaches as an indicator of aerobic functional capacity of the swimmer, not requiring the use of very expensive and sophisticated equipment or procedures involving lengthy and complex calculations. ${ }^{6,8-10}$ Recently, some authors introduced a new trend in critical velocity, associating it with anaerobic performances. ${ }^{11-13}$ These authors found linear relationships between short swimming distances and their respective times and associations with anaerobic race distances, specifically calling as anaerobic critical velocity. This variable seems to represent the functional anaerobic capacity of swimmers, closely associated with performance in $100 \mathrm{~m}$ races. ${ }^{12,13}$ It was suggested that anaerobic critical velocity can be a significant parameter for monitoring anaerobic training and predict the swimmer's performance on short distance events. ${ }^{14,15}$

Thus, knowing that the scientific and technical communities seem increasingly highlighting the importance of the training evaluation and control and the new methods of evaluation that are easy to apply and inexpensive for coaches and swimmers, the aim of the current study was to analyze the aerobic and anaerobic critical velocities in young swimmers throughout a period of 42 weeks of training. It was hypothesized that aerobic and anaerobic critical velocity improved during the 42 weeks of swimming training.

\section{Materials and methods}

\section{Participants}

The sample consisted of 12 swimmers (eight males and four females) of a Portuguese swimming club. All the swimmers and parents were informed of the purpose and methods of the study, and an informed consent was signed. Table 1 presents the sample characteristics. The Institutional Review Board of the Master Degree Course in Sport Sciences of the University of Beira Interior (m3680) approved the study design. The procedures were in accordance with the ethical standards of the responsible committee on human experimentation and with the Helsinki Declaration.

\section{Measures}

The height $(\mathrm{m})$ was obtained by the distance between the ground and the vertex, and the individual was in the vertical position. Body mass $(\mathrm{kg})$ was determined before training session (Tanita TBF 305, Tokyo, Japan) and the body mass index (BMI) $\left(\mathrm{kg} / \mathrm{m}^{2}\right)$ was obtained by dividing weight by the square of height. 
Table I Mean \pm SD values of age, body mass, height and body mass index (BMI)

\begin{tabular}{lllll}
\hline & Age (years) & Body mass $(\mathbf{k g})$ & Height $(\mathbf{m})$ & B.M.I $\left(\mathbf{k g} / \mathbf{m}^{2}\right)$ \\
\cline { 2 - 5 } Mean $\pm S D(n=12)$ & $15.6 \pm 1.78$ & $61.33 \pm 7.9$ & $1.68 \pm 0.09$ & $21.30 \pm 1.70$ \\
\hline
\end{tabular}

The aerobic critical speed $(\mathrm{m} / \mathrm{s})$ was determined by the slope of the linear regression between $50 \mathrm{~m}$ and $400 \mathrm{~m}$ distances and the respective times. Anaerobic critical velocity was determined by the slope of the linear regression between $15 \mathrm{~m}, 25 \mathrm{~m}$ and $50 \mathrm{~m}$ distances and their respective times. The equation of the regression line obtained was of $y=a x+b$ type, where here $y$ is distance swam, $x$ is time and $a=$ critical velocity, $b$ is $y$-interception value. The coefficient of determination $\left(\mathrm{R}^{2}\right)$ was calculated to determine the strength of the regression line equation. These evaluations were carried-out every 4 weeks, starting at week 1 and finishing in the last week of training (week 42), although from weeks 25 to 31 it was not possible to accomplish this aim due to scheduled events.

\section{Procedures}

The period of intervention lasted for 42 weeks of training, between September and June. During this training period, the swimmers performed a total $570.16 \mathrm{~km}$ of total volume of training and 200 training sessions. The Figure 1 represents the training volume, in meters, over 42 weeks of training.

Table 2 presents the number of weeks and total volume in the two macrocycles made over the 42 weeks of training.

Table 3 summarizes the training percentages made in different training periods of the macrocycles. The different training zones were reported as: A1 (Warm-up, Recovery and technical exercises); A2 (Anaerobic Threshold); PA (Aerobic Overload); T. L. (Lactic Tolerance); P. L. (Lactate Production); Velocity. The training periods as P.P.G. (General Preparation Period); P. P. E. (Specific Preparation Period); P.C. (Competitive Period).

In each Macrocycle, the first training phase predominantly included the development of aerobic endurance, while the second phase of the macrocycles, training focused mainly on the development of anaerobic components and velocity.

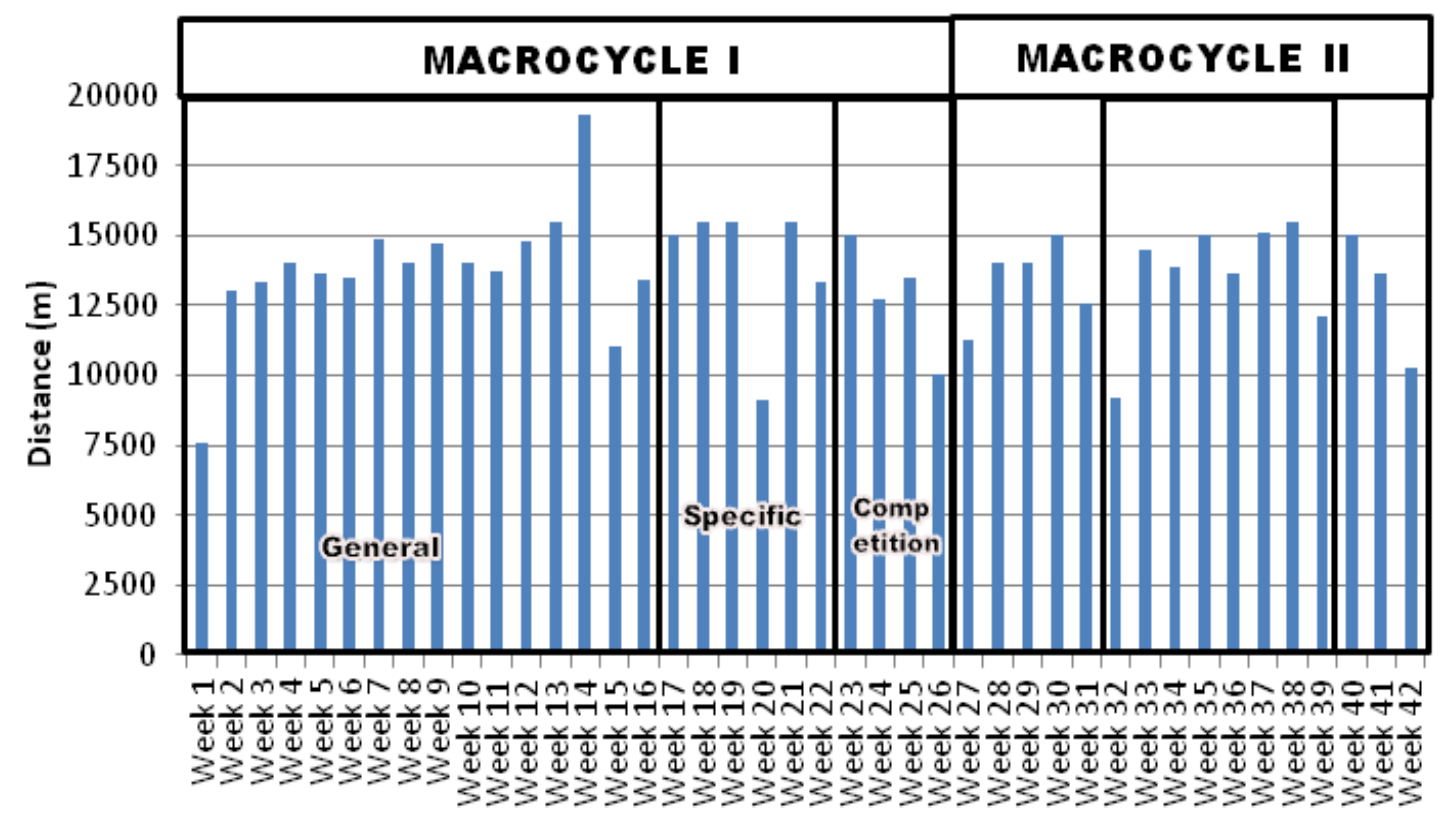

Figure I Training volume, in meters, over 42 weeks of training.

Table 2 Description of macrocyle I and II, in weeks and volume $(\mathrm{km})$

\begin{tabular}{ll}
\hline Macrocycle I & Macrocycle II \\
\hline Between Week I and Week 26 & Between Week 27 and Week 42 \\
Volume: $366.76 \mathrm{~km}$ & Volume: $203.40 \mathrm{~km}$
\end{tabular}

Volume, total volume of training during the macrocycle I and II 
Table 3 Percentage (\%) of training intensities in the two macrocycles conducted over 42 weeks of training.

\begin{tabular}{lllllll}
\hline \multirow{2}{*}{42 Weeks of training } & \multicolumn{3}{l}{ Macrocycle I } & \multicolumn{4}{l}{ Macrocycle II } \\
& P.P.G. & P.P.E. & P.C. & P.P.G. & P.P.E. & P.C. \\
\hline Weeks of training & $1-16$ & $7-22$ & $3-26$ & $7-31$ & $2-39$ & $0-42$ \\
AI & $82 \%$ & $84 \%$ & $91 \%$ & $80 \%$ & $84 \%$ & $91 \%$ \\
A2/PA. & $15 \%$ & $10 \%$ & $2 \%$ & $18 \%$ & $11 \%$ & $1 \%$ \\
T.L./P.L. & $1 \%$ & $3 \%$ & $3 \%$ & $0 \%$ & $2 \%$ & $5 \%$ \\
Vel. & $2 \%$ & $3 \%$ & $4 \%$ & $2 \%$ & $2 \%$ & $3 \%$
\end{tabular}

Training intensities:AI, warm-up, recovery and technical exercises;A2/PA, anaerobic threshold/aerobic overload; T.L./P.L., lactic tolerance/lactate production; Vel., velocity.

Periods of training: P.P.G, general preparation period; P.P.E., specific preparation period; P.C., competitive period

\section{Statistical Analysis}

To verify the normal distribution was performed Shapiro-Wilk test (SPSS). To analyze the aerobic and anaerobic critical velocity during the 42 weeks of training was conducted Paired-Sample T-Test. Comparisons between the first week and the remaining weeks of training were carried out, and the significance level to reject the null hypothesis in all tests was set at $\mathrm{p} \leq 0.05$.

\section{Results}

In Figure 1, it is presented the aerobic critical velocity obtained throughout the 42 weeks. By analyzing the variation in the aerobic critical velocity of swimmers shown above, it can be observed an improvement / maintenance throughout the 42 weeks of training, though there was constant improvement from week 1 to week 17 , following by almost constant values. It was found that the lowest value of the variable was in the first moment of evaluating the same (week 01), while the highest values were found in week 17 and week 35 of training (Figure 2).

Analyzing the Figure 3, there was a gradual increase in anaerobic critical velocity, and there were significant differences at weeks 21 , 35 and 39. Note that the highest values were recorded in the last week of assessments.

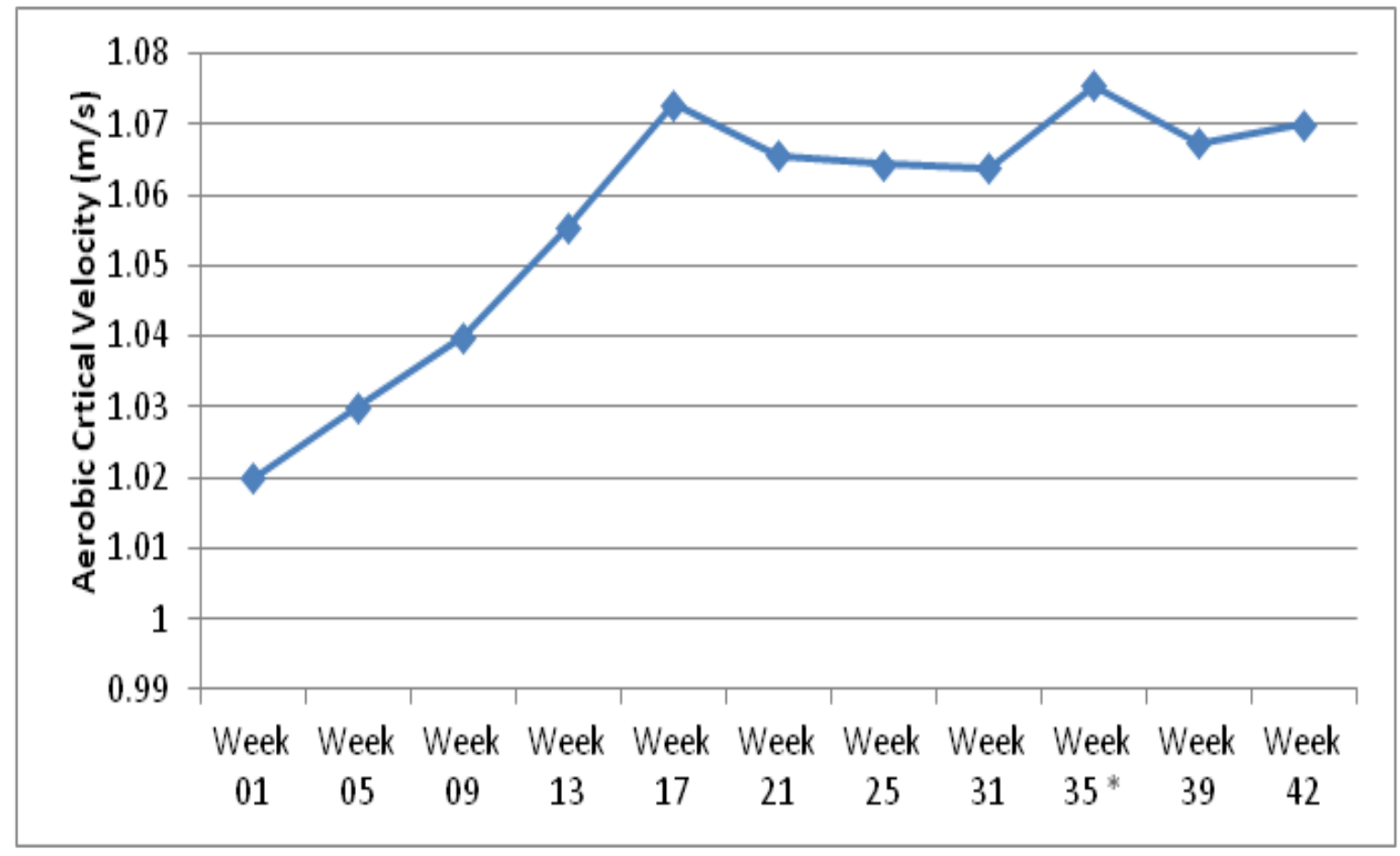

Figure 2 Mean value of aerobic critical velocity $(\mathrm{m} / \mathrm{s})$ of all swimmers over 42 weeks of training $\left({ }^{*} \mathrm{p}<0.05\right)$. 


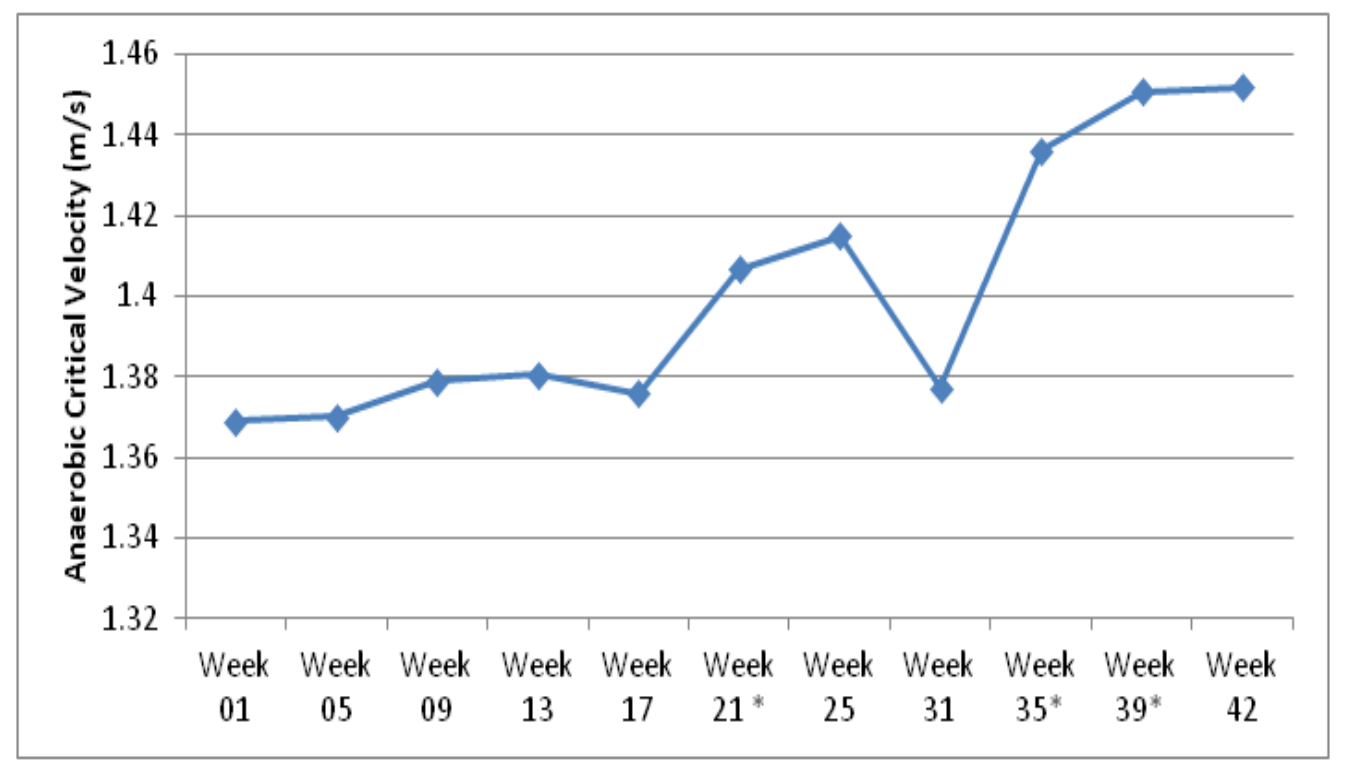

Figure 3 Mean values of anaerobic critical velocity $(\mathrm{m} / \mathrm{s})$ of al swimmers over 42 weeks of training $\left({ }^{*} \mathrm{p}<0.05\right)$.

\section{Discussion}

The aerobic critical velocity has been studied over the years, increasingly being used by coaches as a training control and evaluation variable, being a simple, non-invasive and inexpensive method. ${ }^{9}$ When analyzing the aerobic critical velocity over 42 weeks of training, one can observe that there were improvements from the first to the last week, despite non-significant differences were found between. Nevertheless, significant improvements were found in week 35 , comparing with baseline values, showing a clear improvement in aerobic capacity of the swimmers. Considering the evaluation of aerobic critical velocity carried over different weeks of training, a study by Neto et al. ${ }^{16}$ which aimed to investigate the differences of critical speed over 23 weeks of training, only found significant differences after 20 weeks of training. In similar studies, Marinho et al. ${ }^{5}$ and Machado et al. ${ }^{17}$ found significant differences in the values of the critical velocity at 12 weeks of training. In a study by Reis and Alves, ${ }^{3}$ aiming to determine the relationship between different methods of assessment aerobic capacity and the changes caused by aerobic workout, there were found improvements in the critical velocity of the swimmers at the end of nine weeks of aerobic training. In contrast, Guedes et al. ${ }^{18}$ in thirteen weeks of training with young swimmers, there were no significant differences in aerobic capacity.

Recent studies have been exploring a new trend of critical velocity, using it for determining short distances of swimming relating them to anaerobic performances. ${ }^{11,13-15,19}$ In these studies, were founded strong relationships between the anaerobic critical velocity and performance in the $50 \mathrm{~m}, 100 \mathrm{~m}$ and $200 \mathrm{~m}$ distances. In the current study, when analyzing the anaerobic critical velocity throughout the 42 weeks of training, it appears that there is an improvement. The last few weeks of training showed to be significantly beneficial to this parameter. In fact, it is in this period of training, during season, that the swimmer is training specifically for competition and with higher anaerobic stimulation, as can be seen in the macrocycle design and structure presented in methods section. Considering the evaluation of anaerobic critical velocity over a few weeks of training, a study presented by
Vieira et al., ${ }^{19}$ aiming to characterize the anaerobic performance for 6 weeks of training, there was a significant increase in anaerobic critical velocity. As expected, our values of anaerobic critical speed were lower than those reported by Vieira et al., ${ }^{19}$ due to the lower level of the swimmers participating in the current study (regional level) and due to the younger ages.

Analyzing together the aerobic and anaerobic critical velocity, it can be seen the influence that the different training zones caused in these two variables. Contextualizing, an attempt was made at the beginning of macrocycles to increase aerobic capacity of the swimmers, verifying and as expected, an increase in aerobic critical velocity in those weeks. Knowing that, most of the main swimming events preferred by the current swimmers were the short distances ones, at the specific and competition phase and the arise of the most important competition, the training focused primarily on increasing anaerobic capacity of swimmers. So, as expected, there was a greater increase and significant differences of anaerobic critical velocity variable at the end of the macrocycles. Except for the results obtained at week 35 in both variables, it is clear that when one of the variables has high values, with significant differences, other presents a decrease or maintenance. That is, does not exist a gradual and continuous increase in both aerobic and anaerobic critical velocity during the 42 weeks of training. Marques et al. ${ }^{20}$ found that the higher aerobic critical velocity values corresponded to a maintenance or a slight decrease in values of anaerobic critical velocity, and vice versa.

It can be recognized that there seems to exist some negative correspondence regarding the aerobic-anaerobic training, as the maximization of one seems to correspond with the lower level of the other. ${ }^{21,22}$ However, according Maglisho ${ }^{21}$ there is no consensus on this matter. The same author noted that they can depend on the level of training of the subjects, where the untrained athletes (or a long period of pause) tend to rapidly increase all aspects of performance (aerobic and anaerobic) at the beginning of the season. Only after a few months of training is that performance increase rates decline. ${ }^{23}$ 


\section{Conclusion}

It can be concluded that the training carried out over 42 weeks of training was beneficial for improving aerobic and anaerobic critical velocity of swimmers. In addition, it was shown that the different volumes and intensities influenced the aerobic and anaerobic critical velocity and therefore, aerobic and anaerobic capacities of the swimmers throughout the training periods. When analyzing the aerobic critical velocity over 42 weeks of training, there were improvements from the first to the last week, despite non-significant differences were found between. Nevertheless, significant improvements were found in week 35 , comparing with baseline values, showing a clear improvement in aerobic capacity of the swimmers.

There is a lack of research on the simultaneous study of aerobic and anaerobic critical velocity over a long period of training. Thus, future research should focus on greater understanding of them, especially for monitoring and evaluation of training in swimming.

\section{Acknowledgments}

This project is supported by national funding through the Portuguese Foundation for Science and Technology, I.P., under project UID/DTP/04045/2019

\section{Conflicts of interest}

The authors declare no conflicts of interest.

\section{References}

1. Strzala M, Tyka A. Shaping of Physical endurance and front crawl swimming technique índices in swimmers after half-year training period. Medicina Sportiva. 2007;1(4):88-96.

2. Ortiz E. Estudio de la evolución de las características antropométricas, condicionales y técnicas en nadadores andaluces de grupo de edad. Tese de doutoramento em ciências da actividade física e desporto. faculdade de ciências da actividade física e desporto - universidade de granada, Granada. 2006;274.

3. Reis J, Alves F. Training induced changes in critical velocity and v4 in age group swimmers. Revista Portuguesa de Ciências do Desporto. 2006;6(Supl.2):311-313.

4. Leite R, Leite G, Prestes J, et al. Efeito de um programa de treinamento de 23 semanas nas variáveis antropométricas e neuromusculares em jovens nadadores. Revista brasileira de prescrição e fisiologia do exercício. 2007;1(4):96-105.

5. Marinho D, Silva A, Reis V, et al. Changes in critical velocity and critical stroke rate during a 12 week swimming training period: A case study. Journal Human and Sport Exercise. 2009;4(1):48-56.

6. Wakayoshi K, Ikuta K, Yoshida T, et al. Determining and validity of critical velocity as an index of swimming performance in the competitive swimmer. Eur J Appl Physiol. 1992;64:153-157.

7. Monod H, Scherrer J. The work capacity of a synergic muscular group Ergonomics. 1965;8:329-338.
8. Di Prampero PE, Dekerle J, Capella C, et al. The critical velocity in swimming. Eur J Appl Physiol. 2008;102:165-171.

9. Dekerle J, Pelayo P, Delaporte B, et al. Validity and reliability of critical speed, critical stroke rate and anaerobic capacity in relation to front crawl swimming performances. Int J Sports Med. 2002;23:93-98.

10. Greco C, Denadai B, Pellegrinotti I, et al. Limiar anaeróbio e velocidade crítica determinada com diferentes distâncias em nadadores de 10 a 15 anos: relações com a performance e a resposta do lactato sanguíneo em testes de endurance. Revista Brasileira de Medicina e Esporte. 2003;9(1):1-8.

11. Abe D, Tokumaru H, Niihata S, et al. Assessment of short-distance breaststroke swimming performance with critical velocity. J Sports $S c i$ Med. 2006;5:340-348.

12. Fernandes R, Aleixo I, Soares S, et al. Anaerobic Critical Velocity: a new tool for young swimmers training advice. In: P. Noemie, Beaulieu, editors. Physical activity and children: new research. Nova Science Publishers. New York;2008:211-223.

13. Neiva HP, Fernandes R, Vilas-Boas JP. Anaerobic critical velocity in four swimming techniques. Int J Sports Med. 2011;32: 195-198.

14. Marinho DA, Amorim RA, Costa AM, et al. Anaerobic critical velocity and swimming performance in young swimmers. $J$ Human Sport Exerc. 2011;6:80-86.

15. Marinho DA, Barbosa TM, Silva AJ, et al. Applying anaerobic critical velocity in non-elite swimmers. International Journal of Swimming Kinetics. 2012;1:33-50.

16. Neto J, Prestes J, Leite R, et al. Influence of 23 weeks of training in time and critical speed in young swimmers. Brazilian Journal of Biomotricity. 2009;3(1):130-138.

17. Machado M, Junior O, Marques A, et al. Effect of 12 weeks of training on critical velocity and maximal lactate steady state in swimmers. European Journal of Sport Science. 2011;11(3):165-170.

18. Guedes MJ, Costa AP, Pereira RJS, et al. Sensibilidade da Velocidade Crítica em jovens nadadores durante um macrociclo de treinamento. Brazilian Journal of Biomotricity. 2011;5(3):156-167.

19. Vieira. Projecto de investigação: Velocidade critica anaeróbia em natação pura desportiva. Editora: instituto politecnico da guarda, Guarda; 2013.

20. Marques M. Concepção, planeamento e operacionalização de uma época desportiva de nadadores juvenis do Leixões Sport Clube. Tese de Mestrado em Ciências do Desporto. Faculdade do Porto. Universidade do Porto, Porto; 2013.

21. Maglisho E. Nadando ainda mais rápido. Editora Manole; 1999.

22. Olbrecht J. The Science of Winning. Planning, Periodizing and Optimizing Swim Training . Luton, England: Swimshop; 2000.

23. Fernandes R, Vilas-Boas JP. Critical velocity as a criterion for estimating aerobic training pace in juvenile swimmers. In: Biomechanics and Medicine in Swimming VIII. In: Keskinen K \& Komi P, editors. Gummerus Printing. 1999;233-244. 